\title{
Thermal Performance Comparison of Parabolic Trough Collector (PTC) Using Various Nanofluids
}

\author{
Ashutosh Shirole ${ }^{a *}$, Mahesh Wagha, Vivek Kulkarni ${ }^{b}$ \\ aDepartment of Technology, Shivaji University, District Kolhapur, Maharashtra, India \\ ${ }^{b}$ Sanjay Ghodawat Group of Institutions, Faculty of engineering, Atigre, District Kolhapur, Maharashtra, India
}

\begin{abstract}
The objective of this paper is to investigate the theoretical performance of Parabolic Trough Collector (PTC) using various nanofluids. The theoretical performances are calculated for $\mathrm{Al}_{2} \mathrm{O}_{3}$, graphite, magnetite, $\mathrm{SWCNH}, \mathrm{CuO}, \mathrm{SiO}_{2}, \mathrm{MWCNT}, \mathrm{TiO}_{2}, \mathrm{Fe}_{2} \mathrm{O}_{3}$, and $\mathrm{ZnO}$ in water nanofluids. The heat transfer equations, thermodynamic properties of nanofluid and pumping power are utilised for the development of novel thermal model. The theoretical thermal efficiency of the PTC is calculated, and the economic viability of the technology is predicted for a range of nanofluid concentration. The results showed that the thermal conductivity increases with the concentration of nanoparticles in the base fluid. Magnetite nanofluid showed the highest thermal efficiency, followed by CuO, MWCNT, $\mathrm{ZnO}$, SWCNH, $\mathrm{TiO}_{2}, \mathrm{Fe}_{2} \mathrm{O}_{3}, \mathrm{Al}_{2} \mathrm{O}_{3}$, graphite, and $\mathrm{SiO}_{2}$, respectively. The study reveals that MWCNT at $0.4 \%$ concentration is the bestsuited nanofluid considering thermal gain and pumping power. Most of the nanofluids achieved optimum efficiency at $0.4 \%$ concentration. The influence of mass flow rate on thermal efficiency is evaluated. When the mass flow rate increased from $70 \mathrm{Kg} / \mathrm{hr}$ to $90 \mathrm{Kg} / \mathrm{hr}$, a $10 \%$ $20 \%$ efficiency increase is observed. Dispersing nanofluids reduces the levelized cost of energy of large-scale power plants. These findings add to the knowledge of the scientific community aimed explicitly at solar thermal energy technology. The report can also be used as a base to pursue solar thermal projects on an economic basis.
\end{abstract}

Keywords: PTC thermal performance, heat transfer, PTC performance, Nanofluids, levelized cost of PTC, modelling of PTC, pumping power.

Article History: Received: 28 ${ }^{\text {th }}$ Oct 2020; Revised: 12 ${ }^{\text {th }}$ June 2021 ; Accepted: 27 th June 2021; Available online: 18 ${ }^{\text {th }}$ July 2021;

How to Cite This Article: Shirole A, Wagh, M, Kulkarni V. (2021) Thermal Performance Comparison of Parabolic Trough Collector (PTC) Using Various Nanofluids. Int. Journal of Renewable Energy Development, 10(4), 875-889

https://doi.org/10.14710/ijred.2021.33801

\section{Introduction}

Globally, 80\% of consumed energy comes from fossil fuels (MNRE-UNIDO 2017). However, fossil fuel use has resulted in harmful effects on the environment. Therefore reliance on fossil fuels is being reduced by using renewable energy. Superabundant and free availability of solar energy makes it a popular choice (Biswakarma et al., 2020). Also, it can be utilised as both high grade and lowgrade energy. So more research is focused on solar energy. Applications of Solar energy technology are classified into solar thermal and photovoltaic. However, solar thermal had a lousy run since the last decade and is losing against solar photovoltaic. The reason behind this is the price of electricity generated from photovoltaic solar cells has abated exponentially. However, solar thermal can produce quality and stable power. To make solar thermal systems cost-competitive, the efficiency of solar collectors must be improved. In this direction, much research is focused on thermal performance improvement in solar concentrating collectors.

The conventional heat transport fluid (HTF) used in solar collectors are subjected to poor thermal and absorption properties. These fluids have low heat carrying capacity, which puts a limit on maximum achievable thermal efficiency. It is observed from previous literature that dispersing metallic or non-metallic solid particles in base fluids can break those limits. In the initial stages, micrometre or millimetre solid particles were used, but this led to significant problems like rapid settling of solid particles in fluids and high-pressure drop, which questioned their practical application viability. However, the discovery of nanofluid boosted this concept. Nanofluids are associated with a family of nanotechnology-based HTF composed of conventional heat transfer fluids with nanosized particles dispersed in them to improve their thermal stability. Improved thermal stability is a result of increased surface area, heat capacity, heat transfer rate and high convective heat transfer coefficient. The dispersion of nanofluids also ensures uniform temperature along the receiver's length, which reduces the temperature gradient and drives high thermal performance (Shanthi et al., 2012). Among all solar thermal collectors and technologies, parabolic trough collector (PTC) has shown the most remarkable progress. This can be owed to substantial experience linked with systems. Also, consistent efforts made to establish and nurture small scale manufacturing business as well as micro-enterprises to fabricate and distribute these systems have played a pivotal role in commercializing PTC technology. PTC is 
the most mature technology, due to which it has been the first choice of investors among solar thermal technologies. Lately, various researchers have put forth the concept of nanofluid's application in solar receivers (Hajabdollahi \& Hajabdollahi, 2016). Many experimental and analytical or numerical explorations have already been conducted. However, studies elaborating the application of nanofluid in PTC are not numerous. (Mohammad Zadeh et al., 2015) Earlier in the year 2011, Taylor et al. (2011) investigated graphite nanoparticle with therminol VP-1 as a base a fluid in dish collector and showed 11\% improvement in efficiency. $\mathrm{Li}$ et al. (2011) experimented using $\mathrm{Al}_{2} \mathrm{O}_{3}, \mathrm{ZnO}$, $\mathrm{MgO}$ and concluded that $\mathrm{ZnO}$ is most suitable for nanofluid applications in solar collectors. Vajjha and Das (2012) considered a mixture of water-ethylene glycol as base fluid and dispersed $\mathrm{Al}_{2} \mathrm{O}_{3}, \mathrm{CuO}$, and $\mathrm{SiO}_{2}$ nanoparticles. $\mathrm{Al}_{2} \mathrm{O}_{3}$ nanofluid at $1 \%$ concentration showed a $31.9 \%$ increase in heat transfer coefficient. However, the study is useful for colder regions only. AlMashat and Hassan (2013) examined experimentally $\mathrm{Al}_{2} \mathrm{O}_{3}$ water nanofluid's performance in evacuated $\mathrm{U}$ tube collector. They considered $0.3 \%, 0.6 \%, 1 \%$ of volume concentration which produced $0.6 \%, 6 \%, 28.4 \%$ efficiency enhancement respectively. In a subsequent study, Tyagi et al. (2013) examined $\mathrm{Al}_{2} \mathrm{O}_{3}$ nanofluid theoretically using the finite difference technique, which revealed that 5\% $10 \%$ higher efficiency could be achieved using PTC. Faizal et al. (2013) showed that the plant size of PTC could be reduced by 37\% using MWCNT-water nanofluid. Waghole et al. (2014) experimentally investigated heat transfer network and friction factor of Ag nanofluid in a PTC with and without tape inserts. They observed a $13.5 \%-20.5 \%$ increase in enhancement efficiency. Nagarajan et al. (2014) reviewed nanofluids for solar collector applications, explaining the mechanism of every nanofluid property. They reported that the nanofluid applications are in the early stages, so very few literature pieces of theoretical investigation are available, and more research work is needed to be done.

Bajestan et al. (2015) analysed the heat transfer characteristic of PTC using $\mathrm{TiO}_{2}$ nanofluid and obtained $21 \%$ maximum enhancement of the heat transfer coefficient. Sabiha et al. (2015) performed an experimental investigation of SWCNH water nanofluid in an evacuated tube solar collector and delineated that the highest efficiency of $94.73 \%$ at $0.25 \%$ weight. Later this year, Mwesigye et al. (2015a) performed simulation using ANSYS design modeller and observed that $\mathrm{Al}_{2} \mathrm{O}_{3}$ nanofluid increases thermal efficiency by $35 \%, 74 \%, 76 \%$ at $4 \%, 6 \%$, and $8 \%$ concentration, respectively. Coccia et al. (2016) conducted an experimental study of $\mathrm{Fe}_{2} \mathrm{O}_{3}, \mathrm{TiO}_{2}$, $\mathrm{SiO}_{2}, \mathrm{ZnO}, \mathrm{Al}_{2} \mathrm{O}_{3}, \mathrm{Au}$, water-based nanofluids in PTC and concluded that only $\mathrm{Au}, \mathrm{TiO}_{2}, \mathrm{ZnO}, \mathrm{Al}_{2} \mathrm{O}_{3}$ show a small improvement. No significant improvement is observed compared to water. In a subsequent study, Ghasemi and Ranjbar (2016) analysed PTC with nanofluid using GAMBIT and ANSYS fluent software. They reported that the increase in heat transfer using $\mathrm{Al}_{2} \mathrm{O}_{3}$ is $28 \%$ and $\mathrm{CuO}$ $35 \%$, at 0.03 concentration. Shanthi et al. (2017) provided a review on heat transfer escalation using nanofluids and underlined the important role played by nanoparticles in shaping heat transfer properties. Later this year, Sekhar et al. (2017) experimentally checked thermal efficiency improvement using $\mathrm{Fe}_{2} \mathrm{O}_{3}, \mathrm{Al}_{2} \mathrm{O}_{3}, \mathrm{CeO}_{2}$ in water and obtained 23\%, 25\%, 27\% efficiency improvement compared to the water. In a creative study, Potenza et al. (2017) considered an unusual approach to analyse gas-phase nanofluid with $\mathrm{CuO}$ nanopowder in PTC. The study demonstrates no significant improvement in thermal efficiency. Hoseinzadeh et al. (2017a) experimentally investigated $\mathrm{Al}_{2} \mathrm{O}_{3} /$ Water and SiC/water nanofluid's application in a two-phase closed thermosiphon system. They observed that $2 \% \mathrm{Al}_{2} \mathrm{O}_{3} /$ Water shows a $10 \%$ increase in thermal efficiency, whereas $\mathrm{SiC} /$ water nanofluid having $2 \%$ concentration performs 1.11 times better than pure water. Genc et al. (2017) administered a numerical study employing $\mathrm{Al}_{2} \mathrm{O}_{3}$ nanofluid in flat plate collectors having $1 \%, 2 \%, 3 \%$ concentration of nanoparticles and reported the highest thermal efficiency of $83 \%$ at $0.06 \mathrm{~kg} / \mathrm{sec}$ mass flow rate for $1 \%$ concentration. In the following year, Kasaiean (2018) used MATLAB code to evaluate MWCNT/water nanofluid's effectiveness in PTC and observed a $15 \%$ increment in the convective heat transfer coefficient. Siavashi et al. (2018) studied SWCNH/water nanofluid utilizing MRTLBM code. The particular solar collector employed in the study was of huge interest. He employed direct absorption-type solar receiver. The study stated that nanoparticle addition increases solar absorption, and hence thermal efficiency is improved substantially. On the contrary, increasing the concentration above a specific limit will result in negative performance. Ozsoy and Corumlu (2018) carried out experimental trials on thermosiphon evacuated tube solar collector. They investigated efficacy of $\mathrm{Ag} / \mathrm{H}_{2} \mathrm{O}$ nanofluid as HTF and achieved $20.7 \%-40 \%$ efficiency improvement in thermal efficiency. Kolekar and Patil (2018) analysed the thermal performance of PTC working with $\mathrm{Al}_{2} \mathrm{O}_{3}$ water nanofluid having $0.5 \%$ concentration. They reported a ten percent improvement in thermal efficiency.

Krishna et al. (2018) conducted numerical trials to find better nanofluid for heat transfer in solar flat plate collector. They used ANSYS fluent software and stated that $\mathrm{CuO}$ shows higher efficiency than $\mathrm{Al}_{2} \mathrm{O}_{3}$. Later in the same year, Kang et al. (2018) reported that $\mathrm{CuO} /$ water HTF having 40 nanometers has $2 \%$ high efficiency than nanoparticle having 80 nanometers. Subramani et al. (2018) conducted an experimental exploration using $\mathrm{TiO}_{2}$ deionised water as nanofluid in PTC. They reported 8.66\% thermal efficiency enhancement at $0.2 \%$ volume concentration. In the following year, H. Fathabadi (2019) carried out a theoretical and experimental study to evaluate thermal performance PTC using $\mathrm{CuO}-\mathrm{H}_{2} \mathrm{O}$ Nanofluids for $0.5 \%-3.5 \%$ concentration range. They concluded that adding $\mathrm{CuO}$ nanoparticles up to $1.5 \%$ increases efficiency by $11 \%$. Hoseinzadeh et al. (2019b), again in 2019, numerically investigated pulsating laminar and turbulent $\mathrm{Al}_{2} \mathrm{O}_{3}$ /Water nanofluid flow as $\mathrm{HTF}$ on different flow regimes. The results showed that higher thermal efficiency could be achieved with $\mathrm{Al}_{2} \mathrm{O}_{3} /$ Water relative to water alone; however, it also causes a significant pressure drop across pipe in both turbulent (3000 Reynold no) and laminar (100-2000 Reynold number). In the subsequent study, Hoseinzadeh et al. (2019c) numerically explored pulsating $\mathrm{Al}_{2} \mathrm{O}_{3} /$ Water nanofluid in three different cross channels and made a remarkable observation that increasing volume concentration decreases outlet fluid temperature. They added that nanoparticles lower the heat capacity of fluid, whereas nanoparticles increase heat absorption potential, resulting in increased heat flux.

The literature reveals that $\mathrm{Al}_{2} \mathrm{O}_{3}$, graphite, magnetite $\left(\mathrm{Fe}_{3} \mathrm{O}_{4}\right)$, SWCNH, $\mathrm{CuO}, \mathrm{SiO}_{2}, \mathrm{MWCNT}, \mathrm{TiO}_{2}$, 
$\mathrm{Fe}_{2} \mathrm{O}_{3}$, and $\mathrm{ZnO}$ nanofluids are cited extensively for efficiency improvement in PTC. The aforementioned nanofluids have shown considerable improvements and hence are a potential choice as HTF in PTC. Each nanofluid exhibits different thermodynamic behaviour, which impacts PTC performance differently. Studies published before have considered single to three nanofluids with a limited concentration range. Therefore it becomes indeed necessary to have a comparison of a maximum number of nanofluids. Many researchers have not touched the cost-benefit analysis of PTC using nanofluids. So it can also be incorporated. The primary objective of the paper lies in comparing a range of nanofluids for a wide concentration range. The second objective is to identify the best possible nanofluids for PTC application among all potential choices and calculate their optimum concentration satisfying technical and economic feasibility. In this paper, an effort has been made to compute the theoretical performance of PTC using $\mathrm{Al}_{2} \mathrm{O}_{3}$, graphite, magnetite, $\mathrm{SWCNH}, \mathrm{CuO}, \mathrm{SiO}_{2}, \mathrm{MWCNT}, \mathrm{TiO}_{2}$, $\mathrm{Fe}_{2} \mathrm{O}_{3}$, and $\mathrm{ZnO}$. A theoretical model is tried to develop using all aforementioned nanofluids to find the influence of nanofluid parameters on heat transfer grid of PTC for a wide range of concentration. The study also addresses the economic viability of PTC technology to attract significant investment in various business models for power generation using PTC.

\section{Methodology}

This section covers methodology adopted for the study. It also describes energy equilibrium in PTC and mathematics behind heat transfer framework in PTC. The Fig 1a represents working of PTC. The Fig 1b shows methodology adopted for study. The process starts with determining input parameters. This includes dimensions of PTC, solar irradiance and concentration range of nanofluids. Next nanofluid properties are calculated. Then heat transfer analysis, thermal modelling is done and pumping power is calculated. Finally economic viability of nanofluids application is checked using LCOE and Tpb.

\subsection{Nanofluid properties}

The section describes thermophysical properties nanofluids. These properties are thermal conductivity, density, specific heat and dynamic viscosity of nanofluids. According to Sivashi et al. (Siavashi et al., 2018), the Hamilton crosser model shows a close agreement with experimental data for thermal conductivity of nanofluid.

$$
k_{n f}=k_{b f}\left[\frac{k_{n p}+(n-1) k_{b f}+(n-1)\left(k_{n p}-k_{b f}\right) \emptyset}{k_{n p}+(n-1) k_{b f}-(n-1)\left(k_{n p}-k_{b f}\right) \varnothing}\right]
$$

' $\mathrm{n}$ ' is a shape factor that is 2 for spherical nanoparticles, and $\varnothing$ is the concentration of nanoparticles in water, $k b f$, $k_{n p} k_{n f}$ is the thermal conductivity of the base fluid, nanoparticle, nanofluid, respectively.

The density $(\rho)$ and specific heat $(\mathrm{Cp})$ are calculated as (Siavashi et al., 2018),

$$
\begin{aligned}
\rho_{n f} & =(1-\varnothing) \rho_{b f}+\emptyset \rho_{n p} \\
C p_{n f} & =\frac{(1-\varnothing) \rho_{b f} C p_{b f}+\emptyset \rho_{n p} C p_{n p}}{(1-\varnothing) \rho_{b f}+\emptyset \rho_{n p}} \\
\mu_{n f} & =\frac{\mu_{b f}}{(1-\varnothing)^{2.5}} \\
\mu_{n f} & =\mu_{b f}\left(1+a \emptyset+b \emptyset^{2}\right)
\end{aligned}
$$

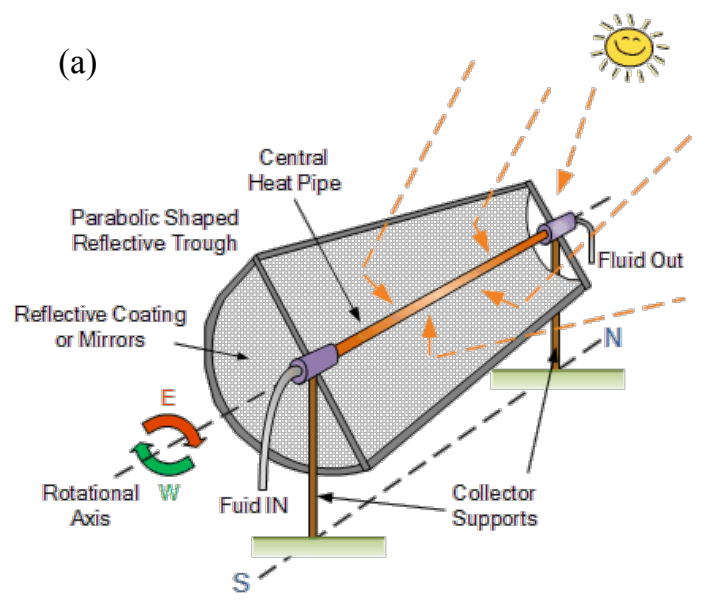

(b)

Input parameters $\left.>\begin{array}{l}\text { Nanofluid } \\ \text { properties }\end{array}\right\} \begin{gathered}\text { Heat transfer } \\ \text { analysis }\end{gathered}>\begin{gathered}\text { Thermal } \\ \text { modelling }\end{gathered}>\begin{gathered}\text { Pumping } \\ \text { power }\end{gathered}>\begin{gathered}\text { Economic } \\ \text { analysis }\end{gathered}$

Fig 1a. Schematic diagram of PTC (Panchal. et al., 2018) and (b) Methodology 
Table 1

Properties of nanoparticles

\begin{tabular}{ccccc} 
Nanoparticle $\mathbf{\rho}\left(\mathbf{k g} / \mathbf{m}^{3}\right)$ & $\begin{array}{c}\mathbf{C p} \\
(\mathbf{J} / \mathbf{k g K})\end{array}$ & $\mathbf{k} \mathbf{( W / m K})$ & $\begin{array}{c}\text { Diameter } \\
(\mathbf{n m})\end{array}$ \\
\hline $\mathrm{Al}_{2} \mathrm{O}_{3}$ & 3970 & 765 & 40 & 47 \\
Graphite & 2210 & 709 & 1950 & 130 \\
Magnetite & 5810 & 670 & 703 & 36 \\
$\mathrm{SWCNH}$ & 1100 & 750 & 6000 & 67 \\
$\mathrm{CuO}$ & 6500 & 533 & 17.65 & 30 \\
$\mathrm{SiO}_{2}$ & 2220 & 745 & 1.38 & 12 \\
$\mathrm{MWCNT}$ & 2100 & 711 & 3000 & 40 \\
$\mathrm{TiO}_{2}$ & 4175 & 710 & 8.4 & 21 \\
$\mathrm{Fe}_{2} \mathrm{O}_{3}$ & 5180 & 670 & 6.9 & 13.3 \\
$\mathrm{ZnO}_{\mathrm{Water}}$ & 5630 & 494 & 27.2 & 30 \\
$\mathrm{Wat}$ & 999.1 & 4179 & 0.613 & - \\
\hline
\end{tabular}

Table 2

Properties of nanofluid

\begin{tabular}{ccccc}
\hline$\varnothing$ & $\rho_{n f}$ & $C p$ & $k_{n f}$ & $\mu_{n f}$ \\
\hline 0.01 & 1226.19 & 3268.55545 & 0.74 & 0.001305 \\
0.02 & 1453.28 & 2642.64362 & 0.90 & 0.001752 \\
0.03 & 1680.37 & 2185.90681 & 1.11 & 0.002447 \\
0.04 & 1907.46 & 1837.92234 & 1.39 & 0.003597 \\
\hline
\end{tabular}

With the help of Brinkman model, effective viscosity $(\mu)$ is computed using the Brinkman model, as shown in equation (4) (Brinkman, 1952). In order to simulate the results under similar circumstances (Bellos \& Tzivanidis, 2018c), general equation (4) is chosen. However, equation (4) shows anomalous results for CNT nanofluids. Hence for these fluids, Fedele (Bobbo et al., 2012) proposed equation (5). It should be noted that the selected model in equation (1), (4), (5) are general models and do not consider nanoparticle diameter and fluid temperature. Nanofluid's thermal conductivity's enhancement and nanoparticle diameter are directly correlated (Sundar et al., 2017a); however, this assessment remains out of scope. The equation particularly considers fluid properties only, but these limitations are shared among all the analyzed nanofluids and yield good result.

\subsection{Material properties}

Analyzing nanofluids' properties is highly relevant since they determine the magnitude of the collector's performance enhancement. Previous literature studies showed that the HTF's thermal properties enhance with nanoparticle concentration (Sandeep and Arunachala, 2017). Howbeit, when the optimum value of concentration in any base fluid is crossed, sedimentation and aggregation phenomenon is observed, which reduces collector performance. This indicates the non-uniform dispersion of nanoparticles in a fluid. Besides, a very high concentration of nanoparticle affects density and viscosity inversely. The density and viscosity cause a significant pressure drop across the pipe, leading to high pumping power to circulate fluid or maintain fluid flow, which is undesirable. The properties of the base fluid and nanoparticles are shown in Table 1. (Hatami and Jing, 2017), (Gorji and Ranjbar, 2016), (Siavashi et al., 2018), (Kim et al., 2016), (Tong, Kim and Cho, 2015),(Bellos, 2018b),(Kaya, Arslan and Eltugral, 2018).

The properties of water-based nanofluid are calculated according to equation (1), (2), (3), (4), (5) for a range of 0 to $10 \%$ nanofluid concentration. The sample calculation of $\mathrm{Al}_{2} \mathrm{O}_{3}$ nanofluid for the range of 0 to $4 \%$ concentration is shown in Table 2. Similar to be followed to $10 \%$ concentration by each nanofluid. Fig. 2 to 5 demonstrates the thermal properties of considered nanofluids. The thermal properties like density, specific heat, thermal conductivity and dynamic viscosity are displayed in response to increasing concentration. These results are validated with Khin et al. (Khin et al., 2017).

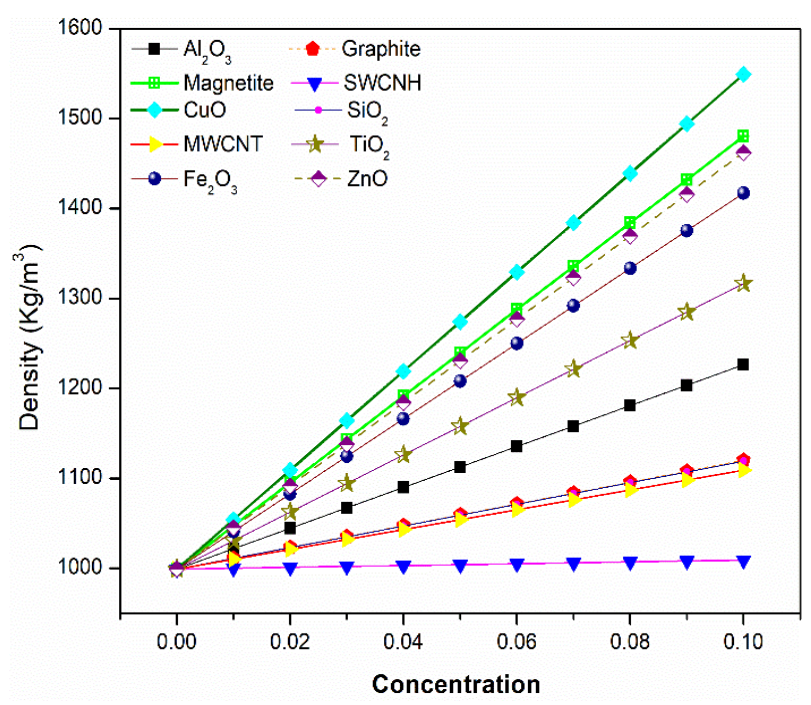

Fig 2. Effect of concentration on density

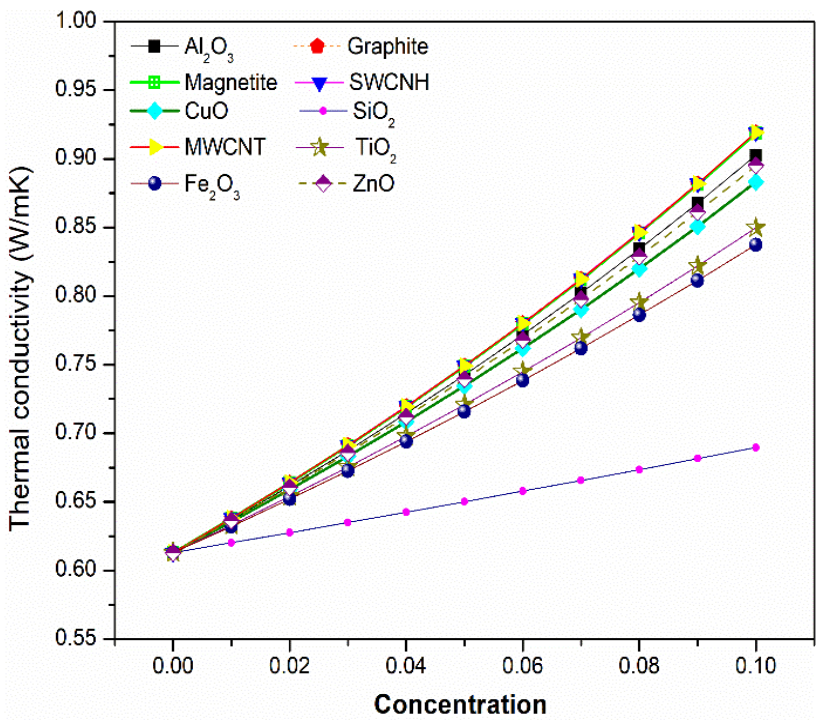

Fig 3. Effect of concentration on $k$ 
Fig. 2 exhibits the effect of nanoparticle concentration on fluid's density. It can be observed that the density of nanofluid increases significantly with an increase in concentration. $\mathrm{CuO}$ nanofluid is having the steepest line compared to other nanofluids, whereas SWCNH has very little influence on water density. The curve for SWCNH is nearly horizontal. The former effect is due to the massive difference in densities of the base fluid and $\mathrm{CuO}$ nanoparticle. Latter is owed to a small difference between densities of water and SWCNH. An increase in density results in high friction factor, causing considerable pressure drop across pipe, which is undesirable effect (Nabati Shoghl et al., 2016).

Fig 3 depicts the effect of nanoparticle concentration on the fluid's thermal conductivity, which governs the heat transfer coefficient. It can be observed that all nanofluids follow a similar trend line with $\pm 0.2 \%$ variation, only $\mathrm{SiO}_{2}$ being an exception. SWCNH, MWCNT and graphite show the highest thermal conductivity enhancement of about $49.96 \%$. It is observed that thermal conductivity increases linearly with concentration. These results are supported by (Yu et al., 2011). The increased thermal conductivity of nanofluids cannot be solely attributed to high thermal conductivity of nanoparticles but also the interaction between nanoparticle and fluid (Simpson et al., 2018).

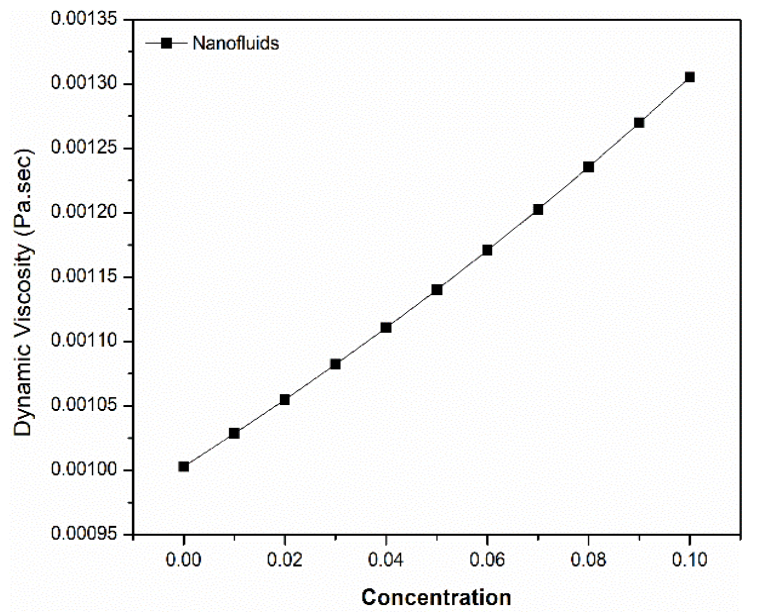

Fig 4. Effect of concentration on $\mu$

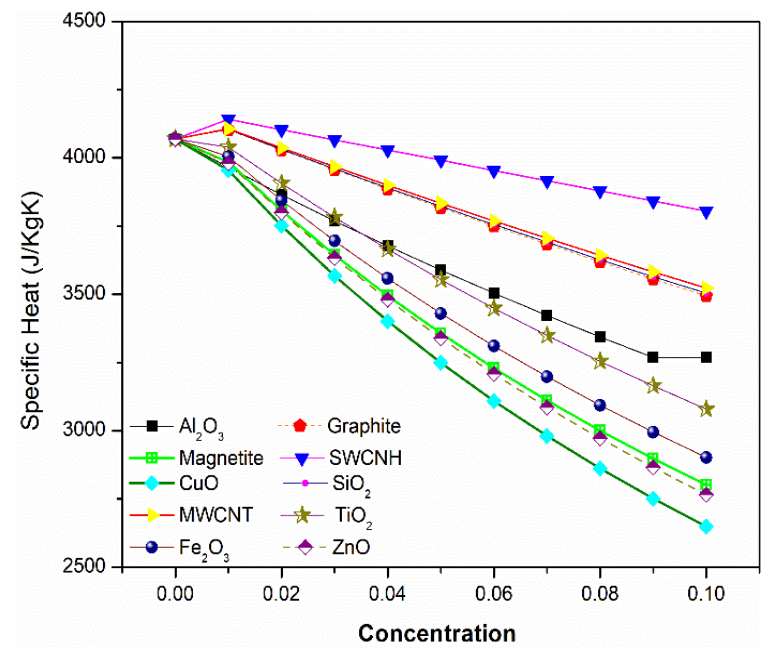

Fig 5. Effect of concentration on $C p$
Thermal conductivity has heavy dominance on Nusselt number and convective heat transfer coefficient. Therefore improved thermal conductivity with concentration prognosticates high thermal performance. Fig 4 reflects the effect of nanoparticle concentration dynamic viscosity. The parabolic curve indicates an exponential increase in dynamic viscosity concerning nanoparticle concentration. Since dynamic viscosity is the only function of concentration rather than nanoparticle properties, as shown in equation (4), all nanofluids have the same viscosity for a given concentration and temperature. It is important to note that viscosity is a measure of frictional resistance between relative layers and therefore increase in same attenuates mobility of fluid (Hussein et al., 2013). As discussed by Hoseinzadeh et al. (2017a), reduced mobility results in increased energy absorption. However, the increased friction between layers engenders highpressure drop and pumping power consumption. Increased dynamic viscosity also leads to sedimentation and augmentation, which is highly undesirable effect. In severe condition, it may lead to pump failure, so optimum concentration must be identified to balance heat gains with pressure drop (Kim et al., 2016b). However, the presence of nanoparticle leads to reduced specific heats shown by Fig 5 . This lends support to previous findings in literature (Murshed, 2011). This is an adverse effect and attributed to the extensively low specific heat of nanoparticles. It is crucial to mention that thermal capacity of fluid is a function of specific heat and density. Therefore decrease in specific heat might result in decrease in heat capacity unless density improves significantly. Hence advantage of increased heat absorption due to high thermal conductivity and viscosity of nanofluid can only be utilized if fluid's heat carrying capacity is high.

\subsection{Parabolic trough collector}

The energy balance equation presented below indicates thermal performance, ultimately calculating the collectors' thermal efficiency under assumed conditions. Heat energy available at parabolic trough collector equals the algebraic sum of energy gained by HTF and losses occurring between receiver collector and environment.

$Q_{u}=m C_{p}\left(T_{o}-T_{i}\right)$

When HTF of specific heat $(C p)$ flowing at a constant mass flow rate $(m)$ enters the receiver with temperature $T i$, it absorbs heat energy, due to which its temperature rises continuously termed as To. Then useful heat gain $(Q u)$ can be calculated as in equation (6). This model is strictly limited to experimental study (Mweigye and Meyer, 2017). A typical thermal performance of PTC is shown by equation (7). (Kalogeriou, 2014). This general model gives more prominence to PTC's geometry.

$Q_{u}=F_{R}\left[S A_{a}-A_{r} U_{l}\left(T_{i}-T_{a m}\right)\right]$ 
Where $S$ is absorbed solar radiation, Aa, Ar is aperture area and receiver area, respectively, $U l$ is the overall heat loss coefficient; $\mathrm{T}_{\mathrm{am}}$ is ambient temperature.

Heat removal factor $\left(F_{R}\right)$ is calculated as in equation (8), where collector efficiency factor $(F)$ is given in equation (9).

$F_{R}=\frac{m C_{p}}{A_{r} U_{l}}\left[1-\exp \left(\frac{-U_{l} F^{\prime} A_{r}}{m C_{p}}\right)\right]$

$F^{\prime}=\frac{\frac{1}{U_{l}}}{\frac{1}{U_{l}}+\frac{D_{r_{0}}}{\left(h_{f} D_{r i}\right)}+\left(\frac{D_{r o}}{2 k}\right)}$

Where Dro, Dri, $h f$, and $k$ represents outside, inside diameter of the receiver pipe, convective heat transfer coefficient of fluid and thermal conductivity of pipe material.

Heat gain can also be represented as a function of convective heat transfer coefficient (Bellows and Tivandis, 2017). It can be referred to as a heat transfer model.

$$
Q_{u}=A_{r i} h_{f}\left(T_{r^{-}} T_{f m}\right)
$$

It is necessary to clarify that Ari is the inner receiver area, $\mathrm{Tr}$ is the mean receiver temperature, and $T_{f m}$ is the mean fluid temperature. $A_{r i}$ and $T_{f m}$ can be calculated according to equation, respectively.

$$
\begin{gathered}
A_{r i}=\Pi D_{r i} L \\
T_{f m}=\frac{T_{i}+T_{o}}{2}
\end{gathered}
$$

The heat transfer coefficient $\left(h_{f}\right)$ is shaped by fluid's thermophysical properties and fluid flow type. It is given as;

$$
h_{f}=\frac{N u k}{D_{r i}}
$$

where $k$ is the thermal conductivity of HTF. For turbulent flow through a circular pipe, Nussult number $(\mathrm{Nu})$ is computed using the Dittus -Boelter equation, which is shown in equation (14) (Bellos and Tzivanidis, 2017a)

$N u=0.023(\operatorname{Re})^{0.8}(\operatorname{Pr})^{0.4}$

Reynolds number (Re) can be calculated as (Hatami and Jing, 2017),

$R e=\frac{\rho V D_{r i}}{\mu}$

Prandtl number $(P r)$ is given as (Bellos and Tzivanidis, 2017a),
$\operatorname{Pr}=\frac{\mu C_{p}}{k}$

Where $\rho, \mu, C_{p}, k$ are the thermophysical properties of water-based nanofluids, and $V$ is velocity of fluid.

The energy available at the solar collector $\left(Q_{s}\right)$ is given as (Kolekar, 2018).

$Q_{s}=\left(I_{b} r_{b}+I_{d} r_{d}\right)(W L)$

Here $I_{b}$ and $I_{d}$ are incident beam and diffused solar radiation, $r_{b}$ and $r_{d}$ are geometric factor for beam and diffused radiation, $\mathrm{W}, \mathrm{L}$ is aperture and length of reflector. Therefore it is appropriate to define thermal efficiency $(\eta)$ as a fraction of total heat available at the collector, which is absorbed by HTF (Bellos and Tzivanidis, 2017a).

$\eta_{t h}=\frac{Q_{u}}{Q_{s}}$

Lastly, pumping power $(P p)$ required to circulate fluid through the receiver is computed. Pumping power requires the friction factor $(f)$ to be determined. The friction factor is dependent on Re. Many researchers have developed a correlation for the friction factor by regression analysis and experimental studies.

For base fluid, the water Blasius equation is used (Azmi et al., 2013);

$f=0.3164 \operatorname{Re}^{-0.25}$

Sundar et al. 2017 (Sundar et al., 2012b) proposed correlation for nanofluid as;

$f=0.3164 R e^{-0.25}(1+\emptyset)^{0.1517}$

Using friction factor, the pressure drop is calculated (Tripathi and Bhong, 2016). The product of volumetric flow per second of HTF inside the pipe and pressure drop across the pipe can be defined as pumping power.

$\Delta P=\frac{f L \rho V^{2}}{2 D_{r i}}$

$P p=\left(\frac{\Pi}{4} D_{r i}^{2} V\right) \Delta P$

\subsection{Economic analysis}

The final aim of the study is to check the economic feasibility of the application of nanofluid in PTC. LCOE is the most crucial parameter used in determining the costeffectiveness of power plants. Analysts also use the total payback period for strengthening the confidence of investors.

Kasaiean et al. (Kasaiean et al., 2018) have put forward below mentioned equation (23) for LCOE. With slight modification as per guidelines of NREL, LCOE is evaluated (Comello, Glenk and Reichelstein, 2017). 
$L C O E=\frac{C_{r f} Z_{\text {investment }}+Z_{\text {maintenance }}}{\text { Wnet } \times C F \times 8760}$

Where $Z_{\text {investment }}$ and $Z_{\text {maintenance }}$ are capital and operation \& maintenance cost per annum, respectively, Wnet is equal to power generation, $\mathrm{CF}$ is equal to the capacity factor. This factor represents a fraction of total running hours throughout the year. This factor is assumed to be $29 \%$.

The $\mathrm{C}_{\mathrm{rf}}$ is capital recovery factor, which is calculated as shown in equation (24).

$C_{r f}=\frac{i(1+i)^{n}}{(1+i)^{n}-1}$

Here $i$ is rate of interest, and $\mathrm{n}$ is the presumed collector's lifetime. The solar thermal power plant compromises various equipment, which includes supportive structure and solar collector (Dai et al., 2003). Ultimate PTC trough collector has been taken into consideration as a solar collector. The cost of the components mentioned above as capital investment is given in Table 3 (Kasaiean et al., 2018)(Kurup et al., 2015)('Nanofluidprice Date 2/10/2020). Kasaiean et al. (Kasaiean et al., 2018) have suggested that maintenance and operating costs can be divided into two sections as variable and one fixed cost is composed of cooperating labour and support cost of chemicals and water has been included in variable costs. In the current study, maintenance and operating cost are estimated to be $8 \%$ of capital cost. Furthermore, the time of return on investment is represented by payback time, which is designated as in equation (25) (Kasaiean et al., 2018).

$T p b=\frac{Z_{\text {investment }}}{\text { Wnet Coe }}$

Coe is the cost of energy, estimated to be $4 \mathrm{INR} / \mathrm{W}-\mathrm{hr}$ as per the latest report.

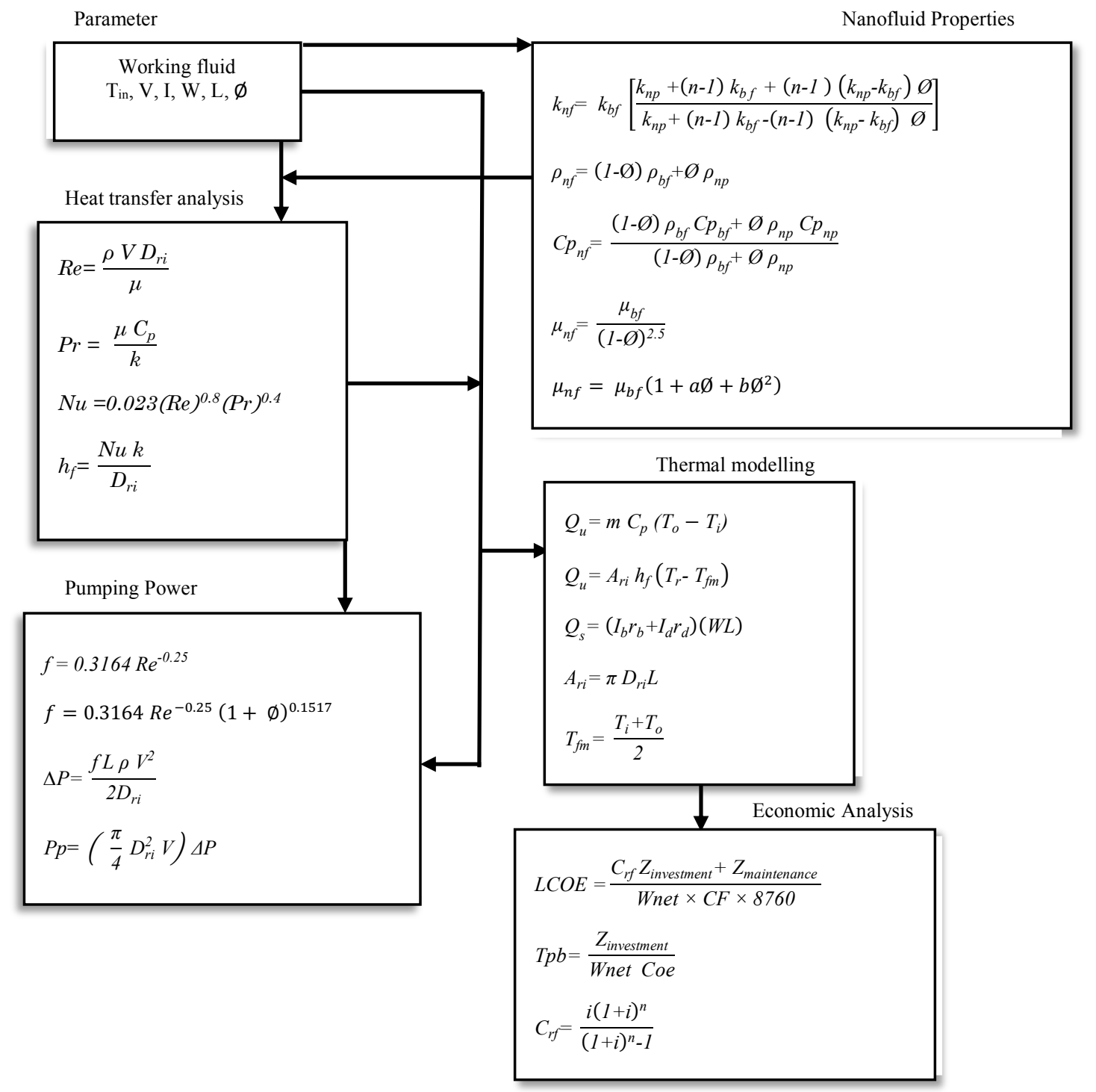

Fig 6. Methodology of model developed 


\subsection{Model selection}

The fundamental dimensions of the solar collector chosen for study are shown in Table 4. It is essential to state that the parameters presented in Table 4 are kept constant throughout the study. The methodology adopted for the study is shown in Fig 6. The first step of study is to calculate nanofluid properties for varying range of concentration. The thermophysical properties of nanofluid are thoroughly analyzed. The next part is heat transfer analysis. This part is important to evaluate impact of heat transfer coefficient and aforementioned dimensionless number on heat transfer behaviour of nanofluid. The third part of study is to model the selected nanofluids in PTC.

As mentioned in section 2.3, there are number of models available to evaluate PTC's performance. The experimental model presented in equation (6) is feasible only to calculate heat transfer performance for limited combinations of nanofluids. The geometric model gives more weight to improvements in the collector's geometry or optical geometry and undermines the significant role of convective heat transfer coefficient. It is noteworthy that nanofluids' use improves the absorption of incident solar radiation. As a result, the convective heat transfer coefficient $(h)$ increases. The geometric model gives mere importance to heat transfer coefficient $(h)$, and hence any changes in $h$ do not show observable effect on the efficiency of PTC in the former model. However, the advantage of using the heat transfer model is that it considers $h$ as a crucial parameter and hence indicates its effect on PTC's efficiency. In accordance with the above context heat transfer model in equation (5) is radially adopted for further calculations.

Using the information presented in Table 4, heat gain is calculated with the aid of equation (5). Further pumping power calculations and economic analysis is performed, respectively. The flow diagram for the methodology adopted is shown in Fig 6. It should be stressed that the main parameters of the considered collector, velocity of fluid flow are kept constant, and all thermophysical properties, dimensionless numbers, thermodynamic constants are calculated for varying concentration of each nanofluid. This accentuates relative comparison of considered cases which is the objective of the research (Bellos and Tzivanidis, 2017a).

Table 3

Capital Cost

\begin{tabular}{lc}
\hline Component & Cost \\
\hline Solar collector & $12000 \mathrm{INR}$ \\
Storage tank & $3000 \mathrm{INR}$ \\
$\mathrm{Al}_{2} \mathrm{O}_{3}$ & $2000 \mathrm{INR} / 15 \mathrm{~g}$ \\
Graphite & $100 \mathrm{INR} / 15 \mathrm{~g}$ \\
Magnetite & $2200 \mathrm{INR} / 15 \mathrm{~g}$ \\
$\mathrm{SWCNH}$ & $30000 \mathrm{INR} / 15 \mathrm{~g}$ \\
$\mathrm{CuO}$ & $2200 \mathrm{INR} / 15 \mathrm{~g}$ \\
$\mathrm{SiO}$ & $2000 \mathrm{INR} / 15 \mathrm{~g}$ \\
$\mathrm{MWCNT}_{2}$ & $2500 \mathrm{INR} / 15 \mathrm{~g}$ \\
$\mathrm{TiO}_{2}$ & $2000 \mathrm{INR} / 15 \mathrm{~g}$ \\
$\mathrm{Fe}_{2} \mathrm{O}_{3}$ & $2000 \mathrm{INR} / 15 \mathrm{~g}$ \\
$\mathrm{ZnO}$ & $2000 \mathrm{INR} / 15 \mathrm{~g}$ \\
\hline
\end{tabular}

Table 4

Specifications of PTC

\begin{tabular}{ccccc}
$L(\mathrm{~m})$ & $D(\mathrm{~m})$ & $I\left(\mathrm{~W} / \mathrm{m}^{2}\right)$ & $R$ & $W(\mathrm{~m})$ \\
\hline 1.21 & 0.011 & 517 & 1 & 1.1 \\
\hline
\end{tabular}

\section{Results and discussion}

The aim of this investigation is to analyse the performance of PTC using nanofluids. The performance of PTC is governed by various parameters like $\mathrm{Nu}$, Re, Pr, heat transfer coefficient. These parameters are closely related to the thermophysical properties of HTF. Since concentration influences these properties, PTC's thermal performance has been evaluated as a function of nanofluid concentration..

\subsection{Dimensionless analysis}

$\mathrm{Re}, \mathrm{Nu}$, Pr regulate fluid flow inside the collector absorber. These quantities vary with HTF used. Therefore it becomes crucial to study the effect of these parameters against nanofluid concentration. Fig 7 represents the effect of nanoparticle concentration on Re. Reynold's number is derived as stated in equation (15). Here to reflect the effect of only concentration, the fluid velocity is kept constant. The results indicate that for $\mathrm{Al}_{2} \mathrm{O}_{3}, \mathrm{SiO}_{2}$ and graphite nanofluids, Reynold's number decreases, whereas for Magnetite, SWCNH, CuO, MWCNT, $\mathrm{TiO}_{2}$, $\mathrm{Fe}_{2} \mathrm{O}_{3}$, ZnO, Reynold's number increases. This phenomenon can be explained by increased density and dynamic viscosity of fluid. Increased Reynolds number shows the dominance of inertia force, whereas receding Reynolds's number shows viscous force dominance.

One of the first attempts is made to show the correlation between the Prandtl number and nanoparticle concentration. Fig 8 illustrates the Prandtl number as a function of concentration. It is clear from the figure that the Prandtl number is inversely proportional to concentration except for $\mathrm{SiO}_{2}$, which shows approximately no change. The graph is steepest in the negative direction for MWCNT, followed by $\mathrm{CuO}$, SWCNH, magnetite, $\mathrm{ZnO}$, $\mathrm{Fe}_{2} \mathrm{O}_{3}, \mathrm{TiO}_{2}$, graphite and $\mathrm{Al}_{2} \mathrm{O}_{3}$.

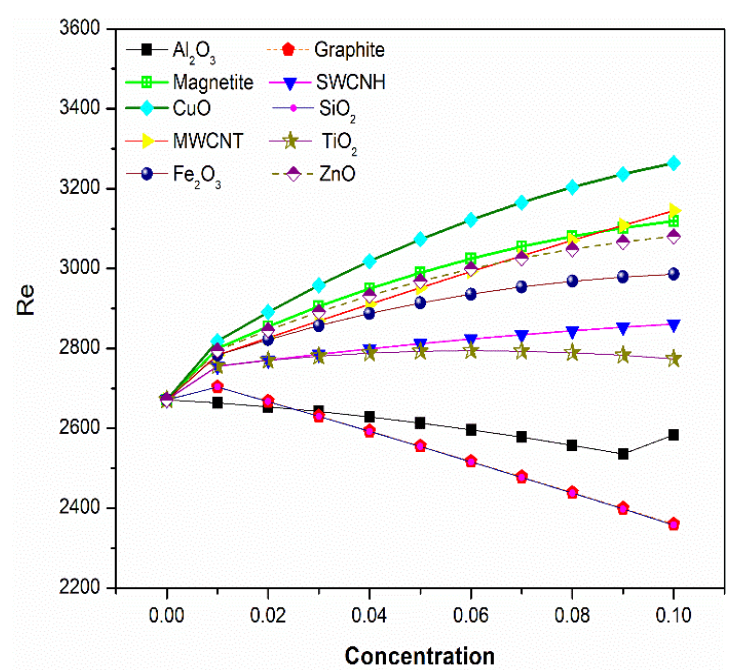

Fig 7. Effect of concentration on Re 


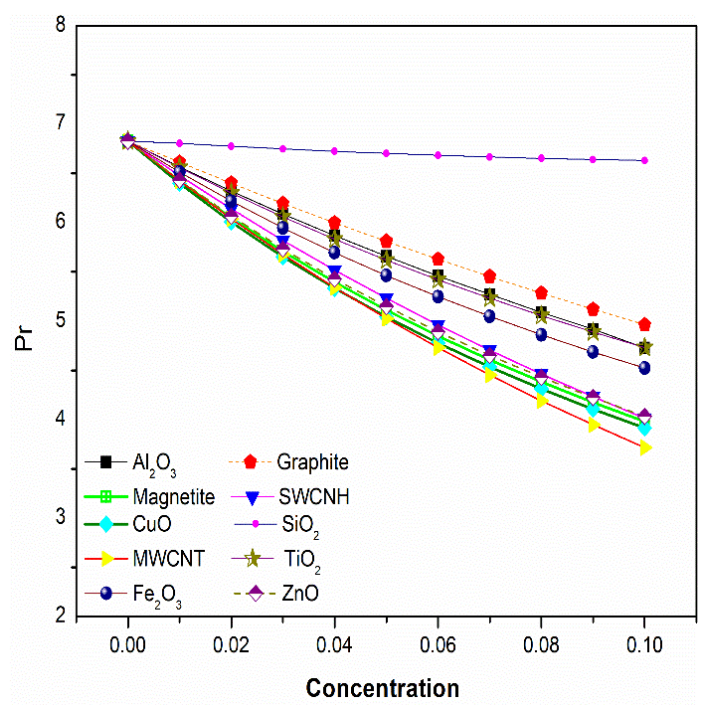

Fig 8. Effect of concentration on Pr

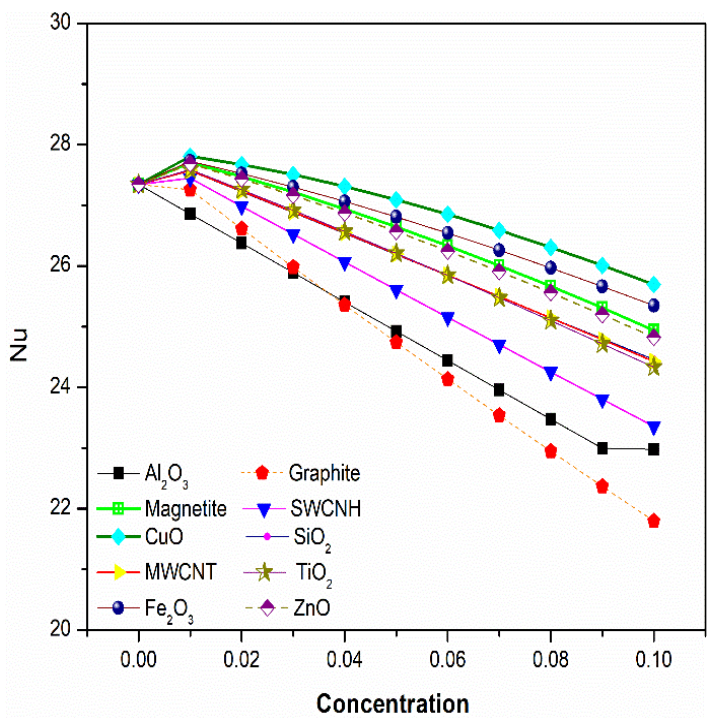

Fig 9. Effect of concentration on $\mathrm{Nu}$

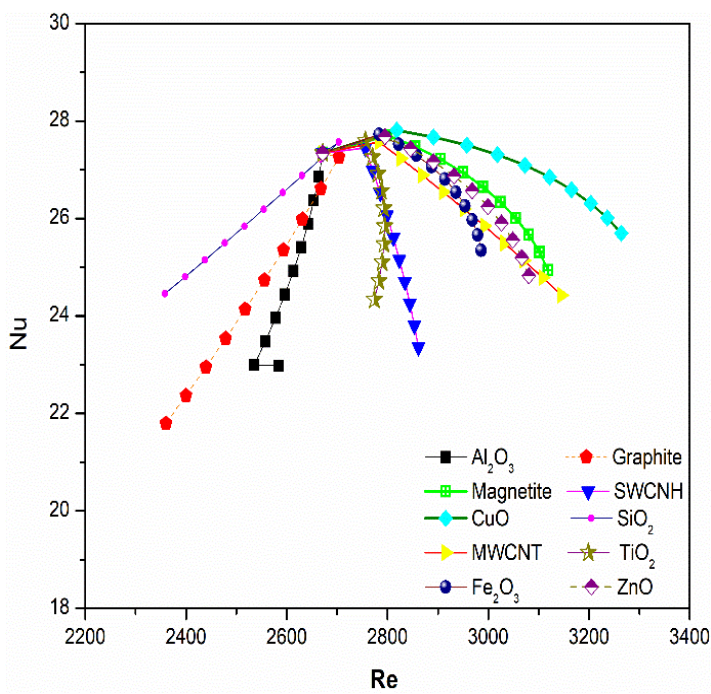

Fig 10. Effect of Re on $\mathrm{Nu}$
Reduced Prandtl number is the combined effect of progressively lower specific heat, reduced mobility and elevated thermal conductivity. The significant lower Prandtl number shows that heat transfer is more likely to happen by thermal diffusion than molecular motion(Smith et al., 2013). The anomalous behavior of $\mathrm{SiO}_{2}$ is due to a low increase in thermal conductivity compared to specific heat.

Fig 9 illustrates the effect of nanoparticle concentration on $\mathrm{Nu}$. It proclaims that as nanofluid concentration rises, Nusselt number decreases (Sadaghiani, Yildiz and Koşar, 2016), which does not support previous research in this area. Mwesigye et al. (Mwesigye, Huan and Meyer, 2015a), Sundar et al. (Sundar, Singh and Sousa, 2014c) have argued that Nusselt number is directly proportional to concentration. However, their calculations are only limited to cases of low concentration. $\mathrm{Nu}$ is the ratio of heat convected to a fluid to the thermal energy conducted within the fluid. Thus the above results are supported by the high thermal conductivity of nanofluid.

Fig 10 exhibits the relationship between $\mathrm{Re}$ and $\mathrm{Nu}$. $\mathrm{Re}$ is plotted on abscissa and $\mathrm{Nu}$ on ordinate axis. The figure proves that Re has no general relation with $\mathrm{Nu}$ and is a fluid dependent phenomenon only. $\mathrm{For}_{2} \mathrm{Al}_{2} \mathrm{O}_{3}$, graphite, $\mathrm{SiO}_{2} \mathrm{Re}$ is directly proportional to $\mathrm{Nu}$, whereas, for rest of the considered nanofluids, Re is inversely proportional to $\mathrm{Nu}$. Therefore based on results, no concrete evidence can be obtained to form general relation between $\mathrm{Re}$ and $\mathrm{Nu}$ for all nanofluids. However, it can be argued that the nusselt number is a function of both Reynolds number and Prandtl number, so above result underline important role played by Prandtl number.

Fig 11 reveals a relation between $\mathrm{Pr}$ and $\mathrm{Nu}$. Since $\mathrm{Nu}$ is a function of Re and $\mathrm{Pr}$ and Re is a fluid dependent phenomenon; it becomes important to project relation between $\mathrm{Pr}$ and $\mathrm{Nu}$. It can be observed that $\mathrm{Nu}$ is directly proportional to Pr. This is due to the high thermal diffusivity of nanofluid. Since thermal diffusivity and thermal conductivity are closely related, $\mathrm{Pr}$ is directly proportional to $\mathrm{Nu}$. This demonstrates how crucial the Pr number is in nanofluid thermal performance assessment (Zhang, 2016).

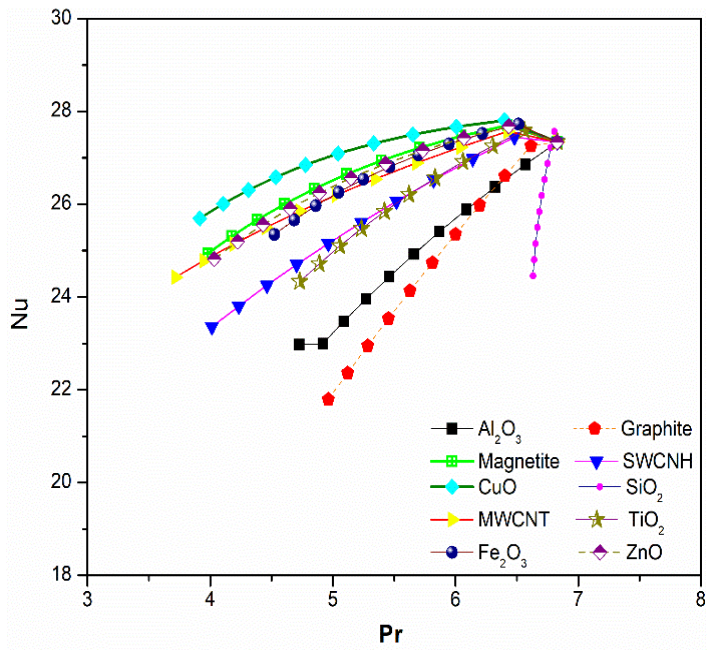

Fig 11. Effect of $\mathrm{Pr}$ on $\mathrm{Nu}$ 


\subsection{Heat transfer coefficient}

Recently published studies have demonstrated the predominance of Re on $\mathrm{h}$. Therefore it is of prime interest to identify significant parameters that govern the heat transfer network. To investigate the relative impact of $\mathrm{Pr}$, Re, and $h$ as a function of concentration, Fig 12 and Fig 13 is plotted. The Figure 12 shows a group of nanofluids of which Re increases with concentration. Figure 13 represents the findings of $\mathrm{Al}_{2} \mathrm{O}_{3}$ nanofluid, which represents the nanofluids group, of which Re decreases with concentration. Fig 12 reveals that Re continuously increases with nanoparticle concentration. Pr decreases continuously, and $h$ increases. Fig 13 surmises that Re decreases with nanoparticle concentration. Pr decreases, and $h$ increases simultaneously. This reveals that enhancement of $h$ is independent of the trend in Re, and $h$ is firmly a function of Pr. It is evident that to achieve a high value of $h$, low Pr is desired. Prandtl number is a relative measure of thermal boundary layer. Therefore decreasing $\operatorname{Pr}$ indicates thinning of thermal boundary layer, thereby increasing $\mathrm{dT} / \mathrm{dx}$ (Temperature gradient). This leads to increased heat transfer. Since heat gain is a product of $\mathrm{h}$ and $\mathrm{dT}$ (Temperature difference), here, the effect of $\mathrm{dT}$ is absorbed in h. Hence the study questions the significance of $\mathrm{Re}$ and casts a new light on the dominance of Pr on heat transfer behaviour of nanofluid.

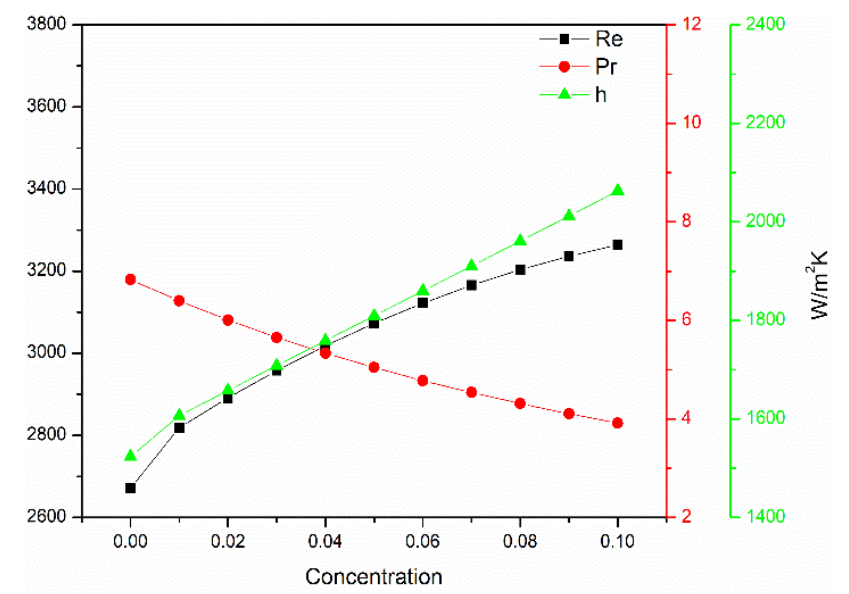

Fig 12. The relative effect of $\varnothing$ on $\operatorname{Re}, \operatorname{Pr}, h$

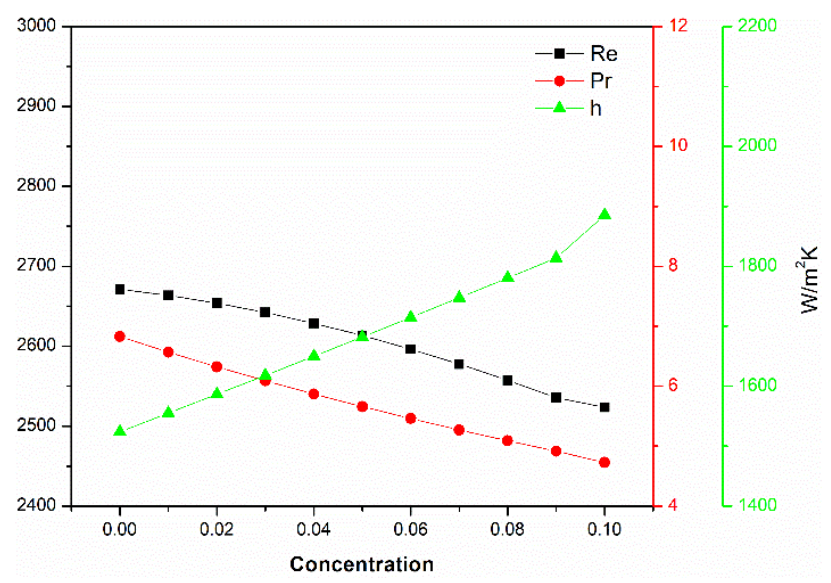

Fig 13. The relative effect of $\varnothing$ on $\operatorname{Re}, \operatorname{Pr}, h$

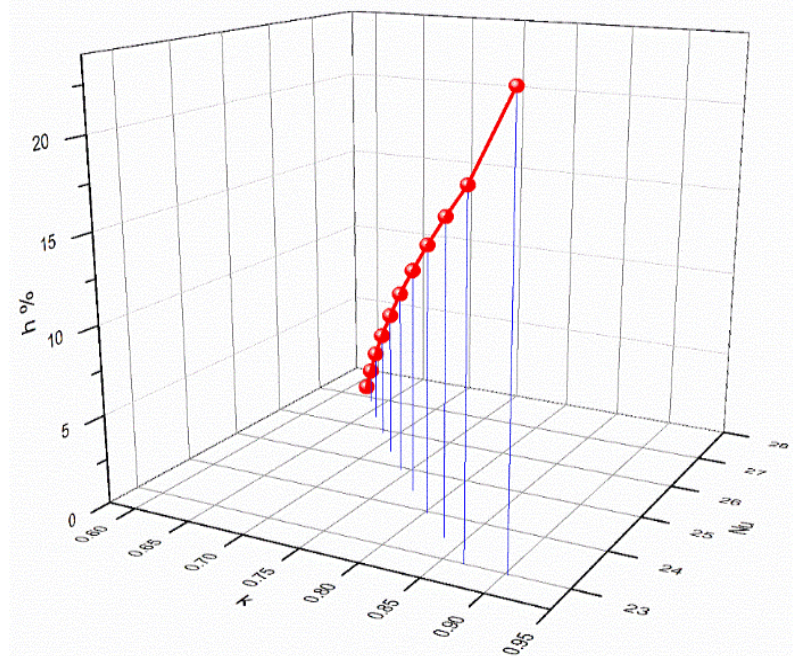

Fig 14. $h$ as a function of $\mathrm{Nu}$ and $k$

Equation (13) states that $\mathrm{Nu}, k$ constrain the heat transfer coefficient. Therefore Fig 14 is plotted as a combined function of $\mathrm{Nu}$ and $k$. The graph is plotted for $\mathrm{Al}_{2} \mathrm{O}_{3}$ nanofluid only; since all nanofluids follow a similar pattern with a small variation. Fig 14 illustrates that $h$ increases when $\mathrm{Nu}$ decreases and thermal conductivity increases. This result is owed to a significant improvement in $k$ relative to declination in $\mathrm{Nu}$. At $10 \%$ concentration $0.9193 \mathrm{~W} / \mathrm{mK}$ of $k, h$ attains a maximum value of 2082 $\mathrm{W} / \mathrm{m}^{2} \mathrm{~K}$.

\subsection{Thermal performance}

Thermal efficiency is derived from equation (18), where $\left(T_{r}-T_{f m}\right)$ is kept constant, and $\eta_{t h}$ is derived for altering values of $h_{f}$. This technique provides commensurate significance to the effect of altering $h_{f}$ on efficiency. Fig 15 displays the relation between $\varnothing$ and $\eta_{t h}$ for concerned nanofluids. Fig 15 infers that Magnetite achieves maximum thermal efficiency enhancement followed by $\mathrm{CuO}$, MWCNT, ZnO, SWCNH, $\mathrm{TiO}_{2}, \mathrm{Fe}_{2} \mathrm{O}_{3}, \mathrm{Al}_{2} \mathrm{O}_{3}$, graphite and $\mathrm{SiO}_{2}$. To check the model's validation, the results are correlated with empirical findings of Kolekar and Patil (Kolekar, 2018). Investigation's output shows good agreement for $\mathrm{Al}_{2} \mathrm{O}_{3}$ nanofluid. The figure shows that the thermal efficacy of PTC using nanofluid increases with nanofluid concentration linearly. It can be observed that the efficiency of $\mathrm{SiO}_{2}$ nanofluid is highest at $1 \%$ concentration. Increasing concentration beyond $1 \%$ decreases efficiency. It must be pointed out that the efficiency of $\mathrm{SiO}_{2}$ nanofluid is still higher compared to water, but the difference is negligible. This is owed to low thermal conductivity of $\mathrm{SiO}_{2}$ nanofluid. At $10 \%$ concentration magnetite, $\mathrm{CuO}$, MWCNT shows 21\%, 19\%, $18 \%$ increases in efficiency, respectively. However, such high gains cannot be achieved practically since high nanofluid concentration causes a heavy pressure drop and hence requires significant pumping power. 


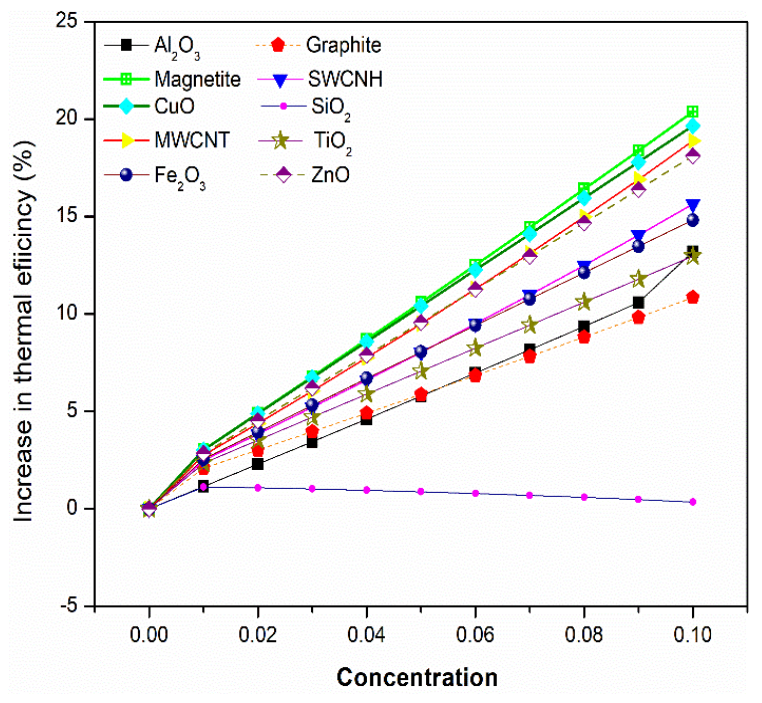

Fig 15. Thermal efficiency

Fig 16 depicts relation between HTF and mass flow rate at $0.4 \%$ concentration. To analyse the results, a particular concentration is chosen, and only mass flow rate is varied. This means all thermophysical properties are constant for a particular fluid in all three different mass rates. By doing this, the emphasis is given to highlight the mass flow rate's influence on thermal efficiency. Regarding prior knowledge, it can be concluded that increasing mass flow rate results in higher efficiency. There are two possible events behind improved thermal efficiency. One is rapid arbitrary movements of molecules and nanoparticles, causing high energy exchange between receiver and nanofluid. However, this also increases friction and hence pressure drop (Hussein et al., 2013). The second one is a decrease in thermal losses occurring between HTF and tube wall of receiver. Fig 16 suggests a direct relationship between mass flow rate and thermal efficiency. When the mass flow rate increases from 70 $\mathrm{kg} / \mathrm{hr}$ to $90 \mathrm{~kg} / \mathrm{hr}$ instantaneous increase of $15-20 \%$ in PTC's thermal efficiency is detected. The data connects well with Genc et al.(Genc, Ezan and Turgut, 2018)

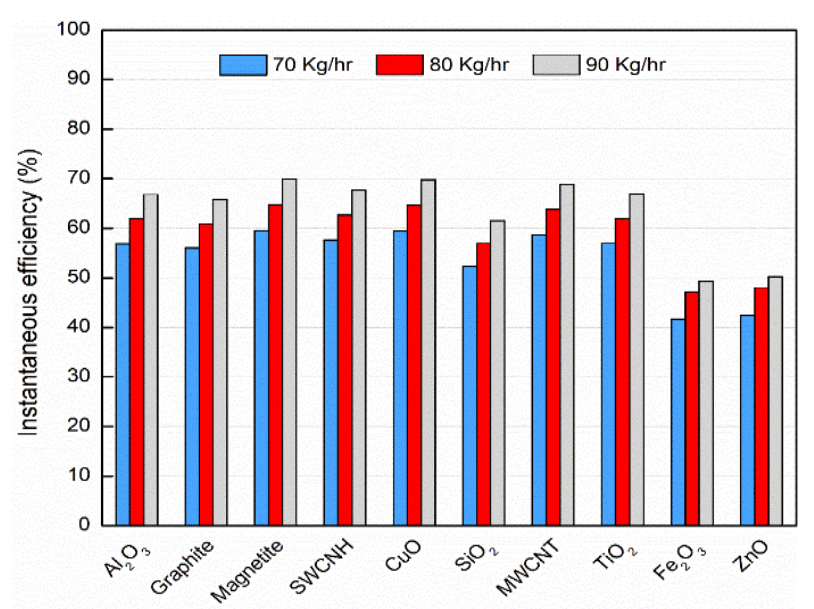

Fig.16 Effect of mass flow rate on efficiency

\subsection{Pumping power}

A considerable amount of power is required to circulate HTF through the collector absorber. For a constant flow rate, pumping power increases as the pressure drop across pipe increases. The pressure drop is calculated using the Darcy Weisbach equation. Pressure drop occurs due to internal friction between fluid layers and friction between fluid and absorber. In the current study, smooth pipe turbulent flow is considered, which reduces fluid friction with absorber to negligible. A high friction factor leads to a high-pressure drop and higher pumping power. A solar collector design is only acceptable if the increase in thermal efficiency outperforms the required pumping power. Hence considerable attention must be paid to the pumping power required by the system.

Fig 17 exhibits friction factor for a varying range of Re. Subramani et al. (Subramani et al., 2017) suggested that $R e$ is inversely proportional to friction factor. The study supports this previous finding. It can be observed that the plot is clustered between 2500 - 3000 Re. It shows that all nanofluids follow a similar pattern. The model showed $\mathrm{a} \pm 2 \%$ deviation with Sundar et al. (Sundar et al., 2017a)

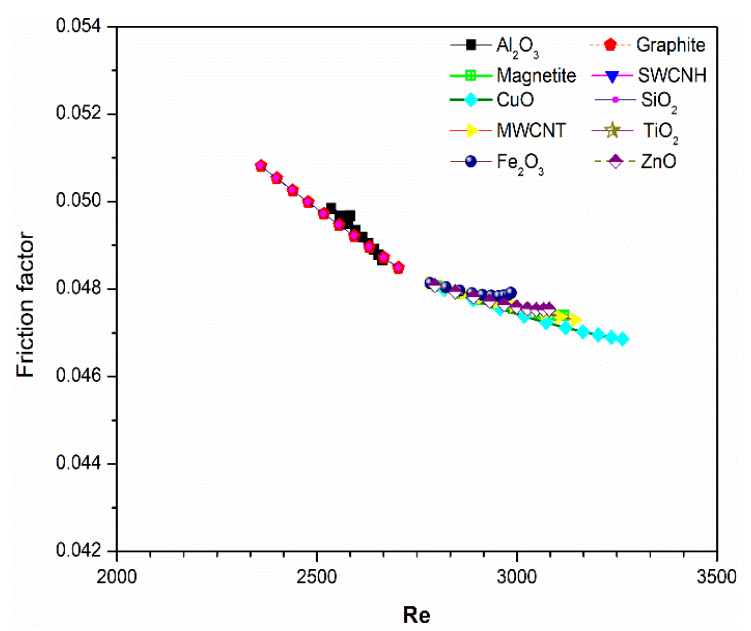

Fig 17. Friction factor

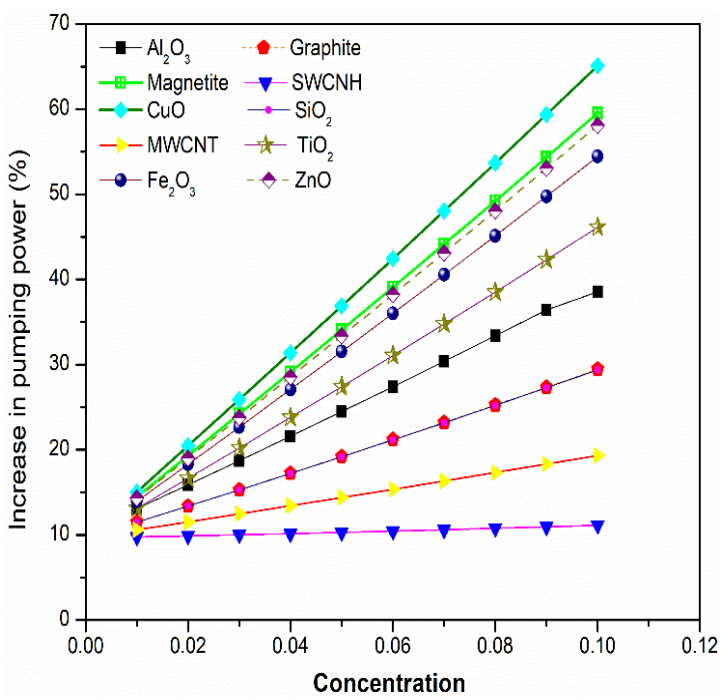

Fig 18. Pumping power consumption 
Fig 18 shows an increase in percentage pumping power consumption against concentration. At $0.1 \%$ concentration, HTF only consumed $10 \%$ of the total energy produced approximately. Indeed increasing concentration resulted in high pumping power requirement. SWCNH showed the least increase in pumping power, whereas $\mathrm{CuO}$ depicts the highest increase in pumping power. Thus SWCNH represents the highest gain in overall efficiency.

\subsection{Economic analysis}

Fig 19 infers LCOE and Tpb of PTC projects using discussed nanofluids. It can be observed that graphite has lower LCOE than water. Every other nanofluid either matches or exceeds the LCOE of water by nominal value. The same results can be observed for $T p b$. These results, therefore, question the economic viability of nanofluids application in PTC. This is the consequence of the high cost of nanoparticles. Nanoparticles constituted 20\% in annual cost. Therefore, if the share of nanofluid's cost can be brought down by lowering the cost of nanoparticles, the technology can prove to be a game-changer in the solar thermal market. It must be emphasized that these results are derived for a very small size set-up and for a $2 \%$ concentration of nanoparticle only. Results might be different for large scale power plants since the share of nanoparticle's cost will be very low compared to the cost of power plant infrastructure.

At the end of the discussion, it can be deduced that Pr plays a crucial role in determining heat transfer characteristics. Hence more research must be done to reexamine the role played by Pr. This study has shed light on the importance of dynamic viscosity of nanofluid. Dynamic viscosity considered in the current investigation only considers the concentration of nanoparticles. Underlining the role played by dynamic viscosity, this investigation proposes further research to develop the formula for dynamic viscosity as a function of shape factor, diameter. Also, this research redraws the attention of the scientific community on the thermal conductivity of nanofluid. The incompetence between dynamic viscosity and thermal conductivity constraints heat transfer behaviour. However, the empirical results reported herein should be considered in light of some limitations.

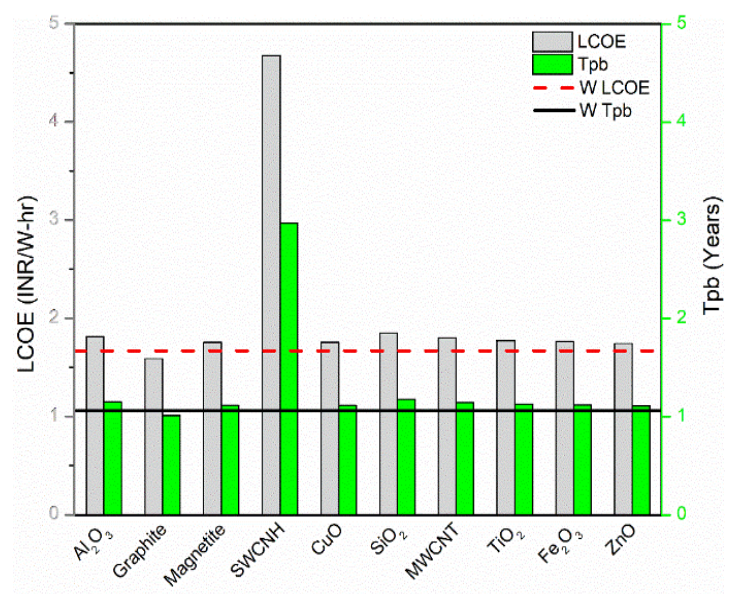

Fig 19. Economic analysis
The effect of temperature on the properties of nanofluid is ignored. Also, the losses occurring due to temperature difference between the receiver and ambient temperature are not considered. The report proclaims that high energy output can be achieved with low investment by using nanofluid, granted that the cost of nanoparticles is within a prescribed limit. Low nanoparticle's cost can further reduce LCOE. Hence further investigation is suggested in this direction.

\section{Conclusion}

This paper investigates the application of nanofluid in PTC. The conventional nanoparticles are selected and examined in water as a base fluid. The thermal performance of PTC using nanofluid is evaluated for a wide concentration range of 0 to $10 \%$. The results showed that high thermal efficiency could be achieved with nanofluid due to improved heat transfer coefficient. The parametric analysis showed that thermal efficiency increases at a high flow rate. When the mass flow rate is increased from $70 \mathrm{~kg} / \mathrm{hr}$ to $90 \mathrm{~kg} / \mathrm{hr}$ an 15 to $20 \%$ increase in instantaneous efficiency is observed. Prandtl number and thermal conductivity of nanofluid influences heat transfer behaviour of nanofluids rather than Reynold's number. Hence, more research must be done to investigate the crucial role played by the Prandtl number.

At $10 \%$ concentration, Magnetite, CuO, MWCNT showed a $21,20,19 \%$ increase in efficiency compared to water and pumping power increases by 59, 65, $19 \%$ compared to water. So it can be concluded that MWCNT is the best suitable nanofluid for PTC application. The consumption through an increase in pumping power and gain in efficiency for all nanofluid is balanced at $4 \%$ concentration and therefore can be considered optimum value for further research. At $4 \%$ concentration, $\mathrm{Al}_{2} \mathrm{O}_{3}$, graphite, $\mathrm{SWCNH}, \mathrm{TiO}_{2}, \mathrm{Fe}_{2} \mathrm{O}_{3}$, and $\mathrm{ZnO}$ showed a 4.6 to $7.8 \%$ increase in efficiency compared to water. The enhanced efficiency of the collector is solely attributed to the high thermal conductivity of nanofluid. $\mathrm{SiO}_{2}$ nanofluid reported only a $0.9 \%$ increase in efficiency and a $17 \%$ increase in pumping power. It shows that pumping power consumption completely outweighs thermal gain and should no longer be considered a viable nanofluid in PTC application.

LCOE is high for small scale application $(<1 \mathrm{MW})$, and hence nanofluids should be considered for large scale power plants only (> $100 \mathrm{MW})$. The research in lowering the cost of nanofluid is crucial for commercialising nanofluid in power sector. This report is fruitful in developing different scales of PTC projects using nanofluid. This study can be used as a base for informing decisions to pursue projects on an economic basis.

\section{Nomenclature}

$\begin{array}{ll}\text { Symbol } & \\ \mathrm{A} & \text { Area, } \mathrm{m}^{2} \\ \mathrm{Crf}_{\mathrm{rf}} & \text { Capital recovery factor } \\ \mathrm{Coe} & \text { Cost of energy, INR/W-hr } \\ \mathrm{Cp} & \text { Specific heat, J/KgK } \\ \mathrm{D} & \text { Diameter, } \mathrm{m} \\ f & \text { Friction factor }\end{array}$


$\mathrm{Nu}$

$\operatorname{Pr}$

$\Delta \mathrm{P}$

$\mathrm{Pp}$

$\mathrm{Qu}_{\mathrm{u}}$

$\mathrm{Q}_{\mathrm{s}}$

$r$

$\mathrm{Te}$

T

W

\section{Greek letters}

$\begin{array}{ll}\rho & \text { Density, Kg/m }{ }^{3} \\ \mu & \text { Dynamic viscosity, Pa.sec } \\ \eta & \text { Efficiency } \\ \varnothing & \text { Concentration }\end{array}$

\section{Subscripts and superscripts}

$\begin{array}{ll}\mathrm{b} & \text { Beam radiation } \\ f & \text { Fluid } \\ \mathrm{fm} & \text { Mean fluid } \\ \mathrm{i} & \text { Inlet } \\ \mathrm{np} & \text { Nanoparticle } \\ \mathrm{nf} & \text { Nanofluid } \\ \mathrm{o} & \text { Outlet } \\ \mathrm{ri} & \text { Inner receiver } \\ \mathrm{r} & \text { Receiver } \\ \text { th } & \text { Thermal }\end{array}$

\section{Abbreviations}

$\begin{array}{ll}\mathrm{Al}_{2} \mathrm{O}_{3} & \text { Aluminium oxide } \\ \mathrm{CNT} & \text { Carbon nanotubes } \\ \mathrm{CuO} & \text { Copper oxide } \\ \mathrm{Fe}_{2} \mathrm{O}_{3} & \text { Hematite } \\ \mathrm{HTF} & \text { Heat transport fluid } \\ \mathrm{INR} & \text { Indian rupees } \\ \mathrm{LCOE} & \text { Levelized cost of energy } \\ \mathrm{MWCNT} & \text { Multi-walled carbon nanotubes } \\ \mathrm{PTC} & \text { Parabolic trough collector } \\ \mathrm{SiO}_{2} & \text { Silicon dioxide } \\ \mathrm{SWCNH}^{\mathrm{T}} & \text { Single-walled carbon nanohorn } \\ \mathrm{TiO}_{2} & \text { Titanium dioxide } \\ \mathrm{ZnO}_{\mathrm{Fe}_{3} \mathrm{O}_{4}} & \text { Zinc oxide } \\ & \text { Magnetite }\end{array}$

\section{References}

Azmi W., Sharma K., Sarma P., Mamat R., Anuar S., Rao V., (2013). Experimental determination of turbulent forced convection heat transfer and friction factor with $\mathrm{SiO}_{2}$ nanofluid, Experimental Thermal and Fluid Science 1-9. https://doi.org/10.1016/j.expthermflusci.2013.07.006

Biswakarma, S., Roy, S., Das, B., \& Kumar Debnath, B. (2020). Performance analysis of internally helically v-grooved absorber tubes using nanofluid. Thermal Science and Engineering Progress, 18(February), 100538. https://doi.org/10.1016/j.tsep.2020.100538

Bellos E., Tzivanidis C. (2017a). Parametric investigation of nanofluids utilisation in parabolic trough collectors, Thermal Science and Engineering Progress, (2017). https://doi.org/10.1016/j.tsep.2017.05.001.

Bellos E. (2018b). A review of concentrating solar thermal collectors with and without nanofluids, Journal of Thermal Analysis and Calorimetry https://doi.org/10.1007/s10973018-7183-1.

Bellos, E., \& Tzivanidis, C. (2018c). Thermal analysis of parabolic trough collector operating with mono and hybrid nanofluids. Sustainable Energy Technologies and
Assessments, 26(August), https://doi.org/10.1016/j.seta.2017.10.005

$105-115$.

Bobbo, S., Fedele, L., Benetti, A., Colla, L., Fabrizio, M., Pagura, C., \& Barison, S. (2012). Viscosity of water based SWCNH and TiO 2 nanofluids. Experimental Thermal and Fluid Science, 36 , $65-71$. https://doi.org/10.1016/j.expthermflusci.2011.08.004

Brinkman H., (1952). The Viscosity of Concentrated Suspensions and Solutions, Journal of chemical and physics. 20(4), 571571. https://doi.org/10.1063/1.1700493.

Coccia G., Di G., Colla L., Fedele L., Scattolini M., (2016). Adoption of nanofluids in low-enthalpy parabolic trough solar collectors : Numerical simulation of the yearly yield, Energy Conversion and Management. 118 306-319. https://doi.org/10.1016/j.enconman.2016.04.013.

Comello S., Glenk G., Reichelstein S. (2017). Levelized Cost of Electricity Calculator: A User Guide, Stanford Graduate School of Business.

Dai, Y. ., Huang, H. ., \& Wang, R. . (2003). Case study of solar chimney power plants in Northwestern regions of China. Renewable Energy, 28(8), 1295-1304. https://doi.org/10.1016/s0960-1481(02)00227-6

Ebrahimnia-bajestan E., Charjouei M., Niazmand H. (2016). Experimental and numerical investigation of nanofluids heat transfer characteristics for application in solar heat exchangers, International Journal of Heat and Mass Transfer. $\quad 92$ 1041-1052. https://doi.org/10.1016/j.ijheatmasstransfer.2015.08.107.

Faizal M., Saidur R., Mekhilef S., Potential of size reduction of flat-plate solar collectors when applying MWCNT nanofluid, (2013). IOP Conference Series: Earth and Environmental $\quad$ Science. $16 \quad 012004$. https://doi.org/10.1088/1755-1315/16/1/012004.

Fathabadi H., (2019). Novel solar collector: Evaluating the impact of nanoparticles added to the collector' s working fluid, heat transfer fluid temperature and flow rate, Renewable.

Energy. https://doi.org/10.1016/j.renene.2019.10.008.

Genc, A. M., Ezan, M. A., \& Turgut, A. (2018). Thermal performance of a nanofluid-based flat plate solar collector: A transient numerical study. Applied Thermal Engineering, $\quad 130, \quad 395-407$. https://doi.org/10.1016/j.applthermaleng.2017.10.166

Ghasemi S., Ranjbar A., (2016) Thermal performance analysis of solar parabolic trough collector using nanofluid as working fluid: A CFD modelling study, Journal of Molecular $\begin{array}{lll}\text { Liquids. } & 222 & 159-166 .\end{array}$ https://doi.org/10.1016/j.molliq.2016.06.091.

Gorji, T. B., \& Ranjbar, A. A. (2016). A numerical and experimental investigation on the performance of a lowflux direct absorption solar collector ( DASC) using graphite, magnetite and silver nanofluids. Solar Energy, 135, 493-505. https://doi.org/10.1016/j.solener.2016.06.023

Hajabdollahi, H., \& Hajabdollahi, Z. (2016). Assessment of nanoparticles in thermoeconomic improvement of shell and tube heat exchanger. Applied Thermal Engineering, 106, 827-837. https://doi.org/10.1016/j.applthermaleng.2016.06.061

Hatami, M., \& Jing, D. (2017). Optimization of Wavy Direct Absorber Solar Collector ( WDASC ) using. Applied Thermal Engineering. https://doi.org/10.1016/j.applthermaleng.2017.04.137

Hoseinzadeh S., Sahebi S.A.R., Ghasemiasl R., Majidian A. (2017a) Experimental analysis to improving thermosyphon (TPCT) thermal efficiency using nanoparticles/based fluids (water), The european physical journal plus, 132 3-10, DOI: 10.1140/epjp/i2017-11455-3

Hoseinzadeh S., Heyns P., Kariman H., (2019b). Numerical investigation of heat transfer of laminar and turbulent pulsating Al2O3/water nanofluid flow, International Journal of Numerical Methods for Heat and Fluid Flow. 30 1149-1166. DOI: 10.1108/HFF-06-2019-0485 
Hoseinzadeh S., Heyns P., Taheri S., Khatir M. (2020c). Numerical investigation of thermal pulsating alumina/water nanofluid flow over three different crosssectional channel, International Journal of Numerical Methods for Heat and Fluid Flow. 30 3721-3735. DOI: 10.1108/HFF-09-2019-0671

Hussein, A. M., Sharma, K. V., Bakar, R. A., \& Kadirgama, K. (2013). The effect of nanofluid volume concentration on heat transfer and friction factor inside a horizontal tube. Journal of Nanomaterials, 2013. https://doi.org/10.1155/2013/859563

Kalogirou A. (2014) Solar Energy Engineering Processes and Systems $2^{\text {nd }}$ edi. Academic press, Oxford

Kasaiean, A., Sameti, M., Daneshazarian, R., Noori, Z., Adamian, A., \& Ming, T. (2018). Heat transfer network for a parabolic trough collector as a heat collecting element using nanofluid. Renewable Energy, 123, 439-449. https://doi.org/10.1016/j.renene.2018.02.062

Kaya, H., Arslan, K., \& Eltugral, N. (2018). Experimental investigation of thermal performance of an evacuated $\mathrm{U}$ Tube solar collector with $\mathrm{ZnO} /$ Etylene glycol-pure water nano fl uids. Renewable Energy, 122, 329-338. https://doi.org/10.1016/j.renene.2018.01.115

Kang W., Shin Y., Cho H. (2019). Experimental investigation on the heat transfer performance of evacuated tube solar collector using $\mathrm{CuO}$ nanofluid and water, Journal of Mechanical Science and Technology, 33 1477-1485. https://doi.org/10.1007/s12206-019-0249-6.

Khin, N., Sint, C., Choudhury, I. A., Masjuki, H. H., \& Aoyama, H. (2017). Theoretical analysis to determine the efficiency of a $\mathrm{CuO}$-water nanofluid based-flat plate solar collector for domestic solar water heating system in Myanmar. 155, 608-619. https://doi.org/10.1016/j.solener.2017.06.055

Kim, H., Ham, J., Park, C., \& Cho, H. (2016). Theoretical investigation of the ef fi ciency of a U-tube solar collector using various nano $f l$ uids. 94, 497-507. https://doi.org/10.1016/j.energy.2015.11.021

Kolekar S., Patil P., (2018). Performance analysis of solar parabolic trough collector system for different concentration of $\mathrm{Al}_{2} \mathrm{O}_{3}$ with water as base fluid, International Research Journal of Engineering and Technology, 5, 2472-2479.

Krishna Y., Razak R. K. A., Afzal A., (2018). The CFD analysis of flat plate collector- nanofluid as working medium, $A I P$ Conference Proceedings https://doi.org/10.1063/1.5079021.

Kurup, P., Turchi, C. S., Kurup, P., \& Turchi, C. S. (2015). Parabolic Trough Collector Cost Update for the System Advisor Model (SAM). November.

Li Y., Xie H. ,Yu W., Li J., Investigation on heat transfer performances of nanofluids in solar collector, Materials Science Forum. $694 \quad$ (2011) 33-36. https://doi.org/10.4028/www.scientific.net/MSF.694.33.

Ministry of New and Renewable Energy - United Nations Industrial Development Organization (MNRE-UNIDO), (2017). India's CST Sector - Vision 2022.

Mohammad Zadeh, P., Sokhansefat, T., Kasaeian, A. B., Kowsary, F., \& Akbarzadeh, A. (2015). Hybrid optimization algorithm for thermal analysis in a solar parabolic trough collector based on nanofluid. Energy, 82, 857-864. https://doi.org/10.1016/j.energy.2015.01.096

Murshed, S. M. S. (2011). Determination of effective specific heat of nanofluids. Journal of Experimental Nanoscience, 6(5), 539-546. https://doi.org/10.1080/17458080.2010.498838

Mwesigye A., Huan Z., Meyer J., (2015a) Thermodynamic optimisation of the performance of a parabolic trough receiver using synthetic oil $-\mathrm{Al}_{2} \mathrm{O}_{3}$ nanofluid, Applied Energy. $156 \quad 398-412$. https://doi.org/10.1016/j.apenergy.2015.07.035.

Mwesigye A., Meyer J., (2017b). Numerical analysis of the thermal and thermodynamic performance of a parabolic trough solar collector using SWCNTs-Therminol®VP-1 nanofluid, Renewable Energy, $119 \quad$ 844-862. https://doi.org/10.1016/j.renene.2017.10.047

Nagarajan P., Subramani J., Suyambazhahan S., Sathyamurthy R. (2014) Nanofluids for solar collector applications: A Review, Energy Procedia. 61, 2416-2434. https://doi.org/10.1016/j.egypro.2014.12.017.

Nanofluid Price - Platonic nanotech private limited. India. Quatotation no- PN/2019-20/1907 (Date- 2/10/2020).

Ozsoy A., Corumlu V., (2018). Thermal performance of a thermosyphon heat pipe evacuated tube solar collector using silver-water nano fluid for commercial applications, Renewable. $\quad$ Energy. $122 \quad 26-34$. https://doi.org/10.1016/j.renene.2018.01.031.

Panchal H., Sadasivuni, K., Muthusamy S., Israr M., Sengottain S. (2021). A concise review on Solar still with Parabolic trough collector. International Journal of Ambient Energy. 1-27 DOI: $10.1080 / 01430750.2021 .1922938$.

Phelan P., Otanicar T., Taylor R. (2013) Solar Energy Harvesting Using Nanofluids-Based Concentrating Solar Collector Journal of Nanotechnology in Engineering and Medicine, 1-9. https://doi.org/10.1115/1.4007387.

Potenza M., Milanese M., Colangelo G., De Risi A., (2017). Experimental investigation of transparent parabolic trough collector based on gas-phase nanofluid, Appl. Energy. $203 \quad 560-570$. https://doi.org/10.1016/j.apenergy.2017.06.075.

Prof A., Saleh S., (2013). Evaluation of Convective Heat Transfer and Natural Circulation in an Evacuated Tube Solar Collector, Journal of engineering, 19 613-628

Sabiha M., Saidur R., Mekhilef R. (2015) An experimental study on Evacuated tube solar collector using nanofluids, Transactions on Science and Technology $242-49$.

Sadaghiani, A. K., Yildiz, M., \& Koşar, A. (2016). Numerical modeling of convective heat transfer of thermally developing nanofluid flows in a horizontal microtube. International Journal of Thermal Sciences, 109, 54-69. https://doi.org/10.1016/j.ijthermalsci.2016.05.022

Shanthi R, Anandan S., Ramalingam V. (2012). Heat transfer enhancement using nanofluids an overview, Thermal Science 16(2) 423-444. DOI: 10.2298/TSCI110201003S

Siavashi, M., Ghasemi, K., Yousofvand, R., \& Derakhshan, S. (2018). Computational analysis of SWCNH nanofluidbased direct absorption solar collector with a metal sheet. Solar Energy, 170(January), 252-262. https://doi.org/10.1016/j.solener.2018.05.020

Simpson, S., Schelfhout, A., Golden, C., \& Vafaei, S. (2018). Nanofluid thermal conductivity and effective parameters. Applied Sciences (Switzerland), 9(1). https://doi.org/10.3390/app9010087

Subramani J., Nagarajan P., Mahian O., Sathyamurthy R., (2017). Efficiency and heat transfer improvements in a parabolic trough solar collector using $\mathrm{TiO}_{2}$ nanofluids under turbulent flow regime Renewable. Energy. https://doi.org/10.1016/j.renene.2017.11.079.

Smith, R., Peters, C., \& Inomata, H. (2013). Heat transfer and finite-difference methods. In Supercritical Fluid Science and Technology (Vol. 4). https://doi.org/10.1016/B978-0444-52215-3.00008-8

Sundar, L. S., Sharma, K. V, Singh, M. K., \& Sousa, A. C. M. (2017a). Hybrid nanofluids preparation, thermal properties, heat transfer and friction factor - A review. Renewable and Sustainable Energy Reviews, 68(March 2016), 185-198. https://doi.org/10.1016/j.rser.2016.09.108

Sundar, L. S., Naik, M. T., Sharma, K. V, Singh, M. K., \& Siva, T. C. (2012b). Experimental investigation of forced convection heat transfer and friction factor in a tube with $\mathrm{Fe} 3 \mathrm{O} 4$ magnetic nanofluid. Experimental Thermal and Fluid Science, $\quad 37, \quad 65-71$. https://doi.org/10.1016/j.expthermflusci.2011.10.004

Sundar, L. S., Singh, M. K., \& Sousa, A. C. M. (2014c). Enhanced heat transfer and friction factor of MWCNT - Fe $3 \mathrm{O} 4 /$ water hybrid nano $\mathrm{fl}$ uids is. International 
Communications in Heat and Mass Transfer, 52, 73-83. https://doi.org/10.1016/j.icheatmasstransfer.2014.01.012

Taylor R., Pehlan P., Otanicar T., Walker C, Nguyen M., Trimble S., Prasher R. (2011). Applicability of nanofluids in high flux solar collectors, Journal of Renewable and Sustainable Energy.3, 023104 https://doi.org/10.1063/1.3571565.

Tong, Y., Kim, J., \& Cho, H. (2015). Effects of thermal performance of enclosed-type evacuated U-tube solar collector with multi-walled carbon nanotube / water nano fl uid. Renewable Energy, 83, 463-473. https://doi.org/10.1016/j.renene.2015.04.042

Tripathi, P. R., \& Bhong, M. G. (2016). Estimation of Heat Transfer Coefficient and Pressure Drop in a Solar Collector Using Fresnel Lenses. 5(2), 2014-2017.

Vajjha R , Das D., (2012) A review and analysis on influence of temperature and concentration of nanofluids on thermophysical properties, heat transfer and pumping power, International Journal of Heat and Mass Transfer.
55

$4063-4078$. https://doi.org/10.1016/j.ijheatmasstransfer.2012.03.048.

Venkata T., Sekhar R., Prakash R., Nandan G., Muthuraman M., (2018). Performance enhancement of a renewable thermal energy collector using metallic oxide nano fluids, Micro \& Nano Letters, 13-2 248-251, DOI: 10.1049/mnl.2017.0410. doi: $10.1049 / \mathrm{mnl} .2017 .0410$

Waghole D., Shrivastva R. (2014) Experimental Investigations on Heat Transfer and Friction Factor of Silver Nanofliud in Absorber / Receiver of Parabolic Trough Collector with Twisted Tape Inserts, Energy procedia, 45 558-567, https://doi.org/10.1016/j.egypro.2014.01.060.

Yu, W., Xie, H., Li, Y., \& Chen, L. (2011). Experimental investigation on thermal conductivity and viscosity of aluminum nitride nanofluid. Particuology, 9(2), 187-191. https://doi.org/10.1016/j.partic.2010.05.014

Zhang, Z.-X. (2016). Effect of Temperature on Rock Fracture. Rock Fracture and Blasting, 111-133. https://doi.org/10.1016/b978-0-12-802688-5.00005-1

(C) 2021. The Authors. This article is an open access article distributed under the terms and conditions of the Creative

Commons Attribution-ShareAlike 4.0 (CC BY-SA) International License (http://creativecommons.org/licenses/by$\mathrm{sa} / 4.0 /)$ 